\title{
O CRISOL: PERIÓDICO DAS ALUNAS DO COLÉGIO AMERICANO (PORTO ALEGRE/RS, 1945-1964)
}

\author{
Dóris Bittencourt Almeida \\ Universidade Federal do Rio Grande do Sul, Brasil.
}

\begin{abstract}
Resumo
Neste trabalho investiga-se o periódico O Crisol, produzido pelas alunas do Colégio Americano, uma escola de Porto Alegre/RS, entre os anos de 1945 e 1964. Esse periódico diz muito à História da Educação, pois evidencia saberes e práticas que circulavam na comunidade do Colégio e revela um pouco das representações da cultura juvenil daquele tempo. Aqui interessam os significados dos discursos difundidos pelo periódico nos processos de subjetivação provocados pelos textos e suas possíveis influências na construção das identidades das jovens leitoras e escritoras do jornal. A pesquisa identifica-se com os pressupostos teóricos da História Cultural e se inscreve no campo das práticas de leitura e escrita e de memórias juvenis, tendo como referenciais as concepções da cultura escrita enquanto produção discursiva de um determinado tempo e lugar.

Palavras-chave: memórias juvenis, escritas escolares, práticas de escrita.
\end{abstract}

\section{O CRISOL: THE JOURNAL BY STUDENTS OF THE COLÉGIO AMERICANO (PORTO ALEGRE/RS, 1945-1964)}

\begin{abstract}
This work investigates the journal O Crisol produced by students of the Colégio Americano, a school in Porto Alegre/RS, between the years 1945 and 1964.The journal says much to the History of Education, as evidenced knowledges and pratices circulating in the community, showing a bit of representations of youth culture in that time. Here the interest by meaning's dissemination of speeches by the journal in the processes of subjectivation caused by texts and their possible influences on the construction of identities of young readers and writers of the newspaper. The research identifies with the theoreticals presuppositions o Cultural History and inscribed in the field of reading and writing practices and memories of youth, taking as reference the concepts of the writing culture as a discursive production of a determinated time and place.
\end{abstract}

Key-words: youth's memories, written school, writing practices. 


\title{
O CRISOL: EL PERIÓDICO DE LAS ALUMNAS DEL COLÉGIO AMERICANO (PORTO ALEGRE/RS, 1945-1964)
}

\section{Resumen}

Este artículo investiga el periódico O Crisol, producido por las alumnas del Colegio Americano, una escuela de Porto Alegre/RS entre los años 1945 y 1964. Lo periódico dice mucho a la Historia de la Educación, como lo evidencia el conocimiento y las prácticas que circulaban en la comunidad del Colegio, revelando un poco de las representaciones de la cultura juvenil de la época. Acá interesan las significaciones de los discursos difundidos por el periódico, en los procesos de subjetivación causados por los textos y sus posibles influencias en la construcción de las identidades de las jóvenes lectoras y escritoras del periódico. La pesquisa se identifica con los presupuestos teóricos de la Historia Cultural y si inscribe en el campo de la lectura y escrita de los recuerdos de la juventud, tomando como referencia los conceptos de alfabetización como producción discursiva de un determinado tiempo y lugar.

Palabras-clave: recuerdos juveniles, escritos escolares, prácticas de escritura.

\section{O CRISOL: PERIODIQUE DES ÉTUDIANTS DU COLÉGIO AMERICANO (PORTO ALEGRE/RS, 1945-1964)}

\begin{abstract}
Résume
Cet étude examine le periodique O Crisol, realisé par les étudiants du Colégio Americano, une école de Porto Alegre/RS, entre les années 1945 et 1964. Le journaux disent beaucoup à l'Histoire de l'Education, comme en témoignant les connaissances et les pratiques qui circulaient dans la communauté, en revelant un peu de representations de la culture de la jeunesse de l'époque. Voici les sens de les intérêts de la difusion des discours diffusés par la revue, dans les processus de subjectivation causés par les textes et leurs influences possibles sur la construction des identités de les jeunes lecttrices et des écrivains du jornal. La recherche identifie les pressupposés théoriques de l'Histoire Culturelle et inscrit dans le domaine de les pratiques de lecture et de l'écriture et des souvenirs de la jeunesse,en prennant comme référence les concepts de la culture écrit comme production discursive d'une époque et lieu.

Mots-clé: souvenirs juvéniles, écrites scolaires, pratiques d'écriture.
\end{abstract}

Quando elas chegam ao Colégio Americano, se distinguem umas das outras apenas pelos nomes que usam. Depois, pouco a pouco cada uma vai se diferenciando pela sua personalidade. Às vezes, essa personalidade apresenta traços de rebeldia, cria problemas, sofre penalidades... muitas vezes torna-se um desafio aos educadores. O tempo vai passando. $E$ dóceis ou rebeldes elas vão conquistando o coração de seus mestres e ajudando a entoar essa melodiosa sinfonia que representa a vida transbordante, buliçosa e alegre de um colégio de meninas e moças. No fim todas tomam jeito e aprendem a gostar desse sistema de vida em que há liberdade com disciplina e responsabilidade. $\mathrm{E}$ depois? Depois vão embora como outras tantas já se foram. Deixam saudades, lembranças das horas vividas a cada dia, das oportunidades que deram e receberam [...]. O maior galardão dos vossos mestres será a contribuição que haveis de levar à sociedade e à pátria e a certeza de que sejam quais forem os caminhos de vossas vidas, sabereis proceder e viver como dignas filhas do Colégio Americano. (JPF, O Crisol, dez., 1957, n. 2, p. 4) 


\section{Periódicos escolares: possibilidades de investigação}

Q uem são essas leitoras e produtoras de um jornal estudantil? Que marcas a escola Ihes deixou? A epígrafe escrita por um professor da escola, João do Prado Flores, anuncia a importância da formação disciplinar que promove a autorregulação e molda a personalidade conforme os valores difundidos pela instituição. Ao adentrar nos escritos dessas moças somos levados a imaginá-las naquele tempo das décadas de 1940, 1950 e 1960. Assim, as filhas do Colégio Americano ${ }^{1}$ e algumas de suas práticas de escrita que sobreviveram ao tempo são o tema deste estudo².

Neste trabalho o corpus documental é constituído por exemplares do jornal O Crisol, produzido pelas alunas do Colégio Americano, uma escola de confissão metodista, localizada em Porto Alegre/RS. Este periódico teve circulação longeva, desde a década de 1930 até o início dos anos 1970. Foram analisadas trinta e cinco edições, entre 1946 e $1964^{3}$, que se encontram no acervo memorialístico da escola, o Museu do Colégio Americano.

A pesquisa se inscreve nos estudos da História da Educação e, especialmente, da história da cultura escrita, sendo esta uma forma específica da história cultural, cuja proposta centra-se na interpretação das práticas sociais de escrever e de ler, tendo como referenciais as concepções da cultura escrita enquanto uma produção discursiva de um determinado tempo e lugar. Castillo Gomez (2001), assim entende as relações entre a história cultural e as práticas de leitura e escrita:

Saber por que razones se há hecho uso de la escritura en cada momento e sociedad, conocer la distribuicion de las capacidades de escribir y de leer, las materialidades de lo escrito y los distintos lugares, espacios e maneras en los que se há experimentado su recepcion y apropriacion, em fin, las practicas de la escritura y de la lectura, es una forma de hacer historia cultural. (p. 96)

A história cultural, como corrente historiográfica que é, contribui para o desenvolvimento da produção de conhecimentos históricos. Suas múltiplas possibilidades investigativas "abriram caminho para a reflexão acerca do fazer do historiador, diante das novidades temáticas e metodológicas que se apresentam" (Fonseca, 2008, p. 71). É neste sentido que a história cultural afirma suas aproximações da História da Educação. Esta, enquanto campo de pesquisa (Nóvoa, 1994), busca construir sua identidade disciplinar, reforçar suas ligações com outras ciências, abrir-se às novas realidades e diversificar as abordagens. Novos estudos têm possibilitado diferentes olhares para o passado educacional e as pesquisas procuram acompanhar essas tendências que redimensionam

${ }^{1}$ Expressão que seguidamente aparece em diferentes edições de $\mathrm{O} C \mathrm{Crisol}$, ao se referir às alunas do Colégio Americano.

${ }^{2}$ O estudo faz parte da pesquisa Escritos de alunos: memórias de culturas juvenis (1940-1960), que tem como objeto de investigação o exame de periódicos estudantis de diferentes instituições escolares privadas, em Porto Alegre/RS. A pesquisa é desenvolvida na Faculdade de Educação da Universidade Federal do Rio Grande do Sul.

${ }^{3}$ A pesquisa teve seu início em $2010 \mathrm{com}$ as análises do periódico O Clarim, produzido pelos alunos do Colégio Farroupilha (Porto Alegre/RS), entre 1945 e 1964. Assim, tomaram-se esses indicadores temporais como referência para análises de periódicos de outras instituições de ensino, a fim de poder estabelecer relações entre eles. 
a produção do conhecimento. As análises dos grandes sistemas e das diretrizes educacionais cedem espaço a investigações que têm como objeto de estudo os sujeitos envolvidos na educação, as discursividades que perpassam suas vidas, seu cotidiano, seus escritos, enfim, suas relações com o mundo.

Para que estudar periódicos escolares? O que eles são capazes de nos dizer acerca do passado? Entende-se que o trabalho com periódicos juvenis sugere inúmeras perspectivas de análise no campo da História da Educação. Segundo Campos (2009), esses documentos "se organizam segundo uma prática social e cultural constituída e constituinte de modos de viver e de pensar, fundamentando-se, por isso num importante veículo educativo para a população desse segmento" (p. 19).

Sendo a vida escolar algo que transversaliza esses escritos, o estudo dos periódicos busca compreender aspectos das culturas escolares, bem como analisar os valores difundidos pela instituição e seu processo de apropriação pelas alunas. Portanto, o propósito não é desvelar, mas multiplicar as relações entre as práticas de escrita e a história da educação das moças alunas do Colégio Americano, nos anos 1940 a 1960.

A escrita aqui é concebida como um lugar de memória da cultura material da escola. Considerando que o textual não é simplesmente uma transposição do real (Viñao Frago, 2001), a investigação está, especialmente, interessada nos significados da difusão dos discursos pelos jornais, nos processos de subjetivação provocados pelos textos escritos e suas possíveis influências nos modos como aquelas jovens pensavam, agiam e se expressavam nos espaços de construção de suas identidades.

Esses jornais, que são entendidos como escritas ordinárias, ou seja, da ordem do comum, não foram produzidos para serem preservados. São registros de memórias que evidenciam fragmentos da cultura escolar de outros tempos. Assim define Maria Teresa Santos Cunha:

menos visibilizados que os livros e quase sempre destinados ao fogo e/ou ao lixo, materiais escolares e documentos produzidos no interior das instituições por alunos e professores são, ainda, mais raros de se encontrar e exigem que os pesquisadores adentrem porões e agucem o olhar à procura de vestígios que guardam memórias da educação escolarizada. (2007, p. 80)

Sabemos que pouco restou da materialidade do passado. Por inúmeros motivos, a maioria dos escritos produzidos já não existem mais. Ana Maria Galvão e Eliane Lopes (2010) explicam que a seleção, com vistas à preservação, é feita ou por quem produziu o material, por quem por algum motivo conserva ou não conserva porque julga não ser relevante, por quem organiza acervos e pelo decurso do tempo. Elas complementam dizendo que "o passado será sempre um conhecimento mutilado, só conta aquilo que foi possível saber a respeito do que se quer saber. $O$ passado é uma realidade inapreensível" (p. 79). Por diversos motivos, por questões afetivas, esses periódicos foram guardados, talvez pelas alunas, por suas famílias e pela instituição escolar zelosa em preservar suas memórias.

Portanto, justamente pelo caráter ordinário, esses jornais dizem muito à História da Educação, dizem muito do processo escolar e evidenciam saberes que circulavam naquele momento, naquela comunidade. São "documentos/monumentos" (Le Goff, 1996, 
p. 545), que possibilitam aproximações da cultura escolar daqueles tempos, especialmente da educação de moças que, de certa forma, se materializa nos textos publicados. Esses escritos, entendidos como fragmentos de memórias, constituem-se em um importante veículo educativo para seus leitores e revelam um pouco da história da instituição educativa em questão, o Colégio Americano.

A partir da leitura de $O$ Crisol é possível chegar perto do universo social e cultural daquelas estudantes, pois seus registros traduzem um pouco do cotidiano escolar e mostram indícios de saberes e de práticas escolares vinculadas a preceitos de civilidades. Os jornais apresentam evidências da vida daquelas moças, indicam sua posição social, seus valores, sua religiosidade.

Mas o que pode ser feito com este documento? Sabe-se que ele não fala por si só, é preciso estranhá-lo, desnaturalizá-lo, provocá-lo. Que perguntas podem ser feitas a ele? Que narrativas do passado são evidenciadas? Ao escrever, o que falavam, de onde falavam por que e para quem falavam?

\section{Um pouco da história do Colégio Americano}

A criação do Colégio Americano está relacionada à história do protestantismo norteamericano no Brasil ${ }^{4}$. No século 19 imigrantes norte-americanos para cá vieram como representantes dos princípios da liberdade e democracia e, imbuídos desses ideais, criaram escolas. Metodistas, presbiterianos e batistas tinham em comum os propósitos de evangelizar e educar a nação. Portanto, a influência dessas igrejas é reconhecida antes no campo educacional do que no religioso, como estratégia de suprir as necessidades dos imigrantes de fala inglesa.

A pedagogia desenvolvida nos colégios protestantes, de acordo com a ideologia liberal, colocava como meta individual o êxito e o progresso da sociedade. Importa dizer que tal pedagogia valorizava a educação das mulheres, incentivava a formação de valores burgueses identificados ao trabalho e ao metodismo, enfatizava as ciências nos currículos e priorizava a formação de valores cristãos ${ }^{5}$.

No final do século 19, com o intuito de fundar um campo missionário e uma obra educacional, alguns missionários da Igreja Metodista ${ }^{6}$ de Montevidéo, Uruguai, chegaram ao Rio Grande do Sul. Essa primeira congregação metodista do Rio Grande do Sul tinha como pastor João da Costa Corrêa. Com ele vieram mais seis membros, entre eles quatro mulheres. Uma delas era Carmem Chacon.

Com suas bases calcadas nos idéias de John Wesley, fundador do Metodismo na Inglaterra, os missionários promoveram ações de evangelização, criação de escolas e desenvolvimento de obras sociais para os mais necessitados em diversas cidades, iniciando pelo interior do Estado até chegar a Porto Alegre.

Assim, em 1885, João da Costa Corrêa chegou a Porto Alegre e junto com sua família veio a jovem professora Carmen Chacon. No ano seguinte, Chacon fundou o Colégio Evangélico Misto n. 1, em um prédio alugado na Praça General Marques, hoje

\footnotetext{
${ }^{4}$ Para maiores informações sobre esse assunto, ver Mesquida (1994).

${ }^{5}$ As informações referentes à história do Colégio Americano foram consultadas em diferentes edições da Revista Metodista de Educação do Sul n. 7 e 8, disponível em <http://www.metodistadosul.edu.br/ institucional/redeipa/historico_metodismo.php>. Acesso em: 22 mar. 2011.

${ }^{6}$ Movimento de renovação espiritual fundado por John Wesley, no século 18, na Inglaterra.
} 
Rua dr. Flores, localizada no centro histórico da cidade. Neste colégio, João Corrêa era o diretor e Carmem a professora. No ano seguinte, a fim de atender aos pedidos de matrícula, a instituição foi desdobrada em Colégio Evangélico Misto n. 1, 2 e 3. Essas são as origens mais remotas do Colégio Americano.

O Crisol, em 1957, apresenta um texto acerca da vida de Carmem Chacon: "Menina miudinha de lindos olhos negros e sorriso doce, assim era Carmem Chacon que de um momento para outro viu seu sonho juvenil realizado de ser professora" ( $O$ Crisol, jun., 1957 , n. 1, p. 6). Segundo a narrativa, Carmem havia nascido em uma pequena localidade no Uruguai, em 1869 e, aos doze anos, o missionário João Correa teria trazido a menina para Montevidéo para que estudasse no curso especializado da professora Teresa Calvet. A narrativa prossegue: "Carmem, apesar da distância da sua terra e de sua família, achou-se num lar harmonioso onde transformou-se numa moça que dedicou a sua vida ao Senhor. Tornou-se colaboradora eficiente na Escola Dominical" (Ibid., p. 6).

Carmen Chacon faleceu em 1889, durante viagem ao Uruguai, por tuberculose. A partir de então o colégio ficou a cargo da Divisão de Mulheres da Igreja Episcopal do Sul que, além de fazer a supervisão educacional, auxiliava a instituição com recursos financeiros e pessoal. $O$ popularmente conhecido Colégio das Americanas passou a chamar-se Colégio Americano nas primeiras décadas século 20, sendo uma escola apenas para meninas.

Impressiona o quanto a história da uruguaia Carmem Chacon é recorrente nas páginas de $\mathrm{O}$ Crisol. Em todas as narrativas analisadas há um tom de sacralidade à jovem professora. Sua breve trajetória de missionária e fundadora do colégio marcou a história da instituição: "O Colégio Americano nasceu do amor cristão de uma jovem estrangeira" e "O atual Colégio Americano é o maior espelho da bondade de Carmem, uma menina uruguaia que, longe de sua pátria, semeou esta semente cujo fruto está beneficiando a mais de mil alunas" (p. 3). A escola elegeu como ícone de suas memórias uma mulher, professora, estrangeira, que faleceu precocemente, dedicando-se integralmente à obra missionária e educativa. Uma de suas frases, publicada no Crisol de novembro de 1960, é "Combati o bom combate, acabei a carreira, guardei a fé". A biografia de Carmem Chacon foi escrita por um dos professores da escola, João Flores, em 1955. Intitulado "Seu maior amor: uma vida a serviço de Deus", o livro foi amplamente divulgado nas páginas do jornal:

Foi assim a vida de Carmem Chacon, a jovem professora que com três crianças no longínquo 1885 iniciou as atividades educacionais no nosso querido Americano. SEU MAIOR AMOR é o título do livro que conta a história comovente de seus vinte anos de vida. Peça o livro diretamente na Secretaria ou pelo Reembolso Postal. Custa apenas 20,00. (O Crisol, out., 1955 , n. 2, p. 5)

A escola cresceu e precisou ocupar outros espaços. Foi assim que, em 1921, o colégio teve seu primeiro prédio próprio, situado na Avenida Independência, rua de imponentes residências no início do século 20. Em 1926 a Divisão de Mulheres adquiriu um terreno no bairro Petrópolis, na época região afastada do centro da cidade. Em 1945, a escola transferiu-se para Petrópolis e lá se encontra até hoje, tendo a colaboração da 
arquiteta e diretora da escola na época Mary Sue Brown.

A escola foi pioneira em relação à escolarização das mulheres pela variedade de cursos oferecidos, alguns deles profissionalizantes. Nos anos 1950, além dos cursos nas modalidades Normal, Clássico e Científico, introduziu a formação em Economia do Lar. Em 1952 criou o primeiro curso Secretariado do Brasil, bem como o curso de Dietista Escolar. Em 1967 foram extintos os cursos de Economia do Lar e Dietista Escolar e criado o Curso Técnico Industrial de Alimentação ${ }^{7}$. Essa preocupação com a formação profissional das alunas evidencia o significado desta instituição de ensino e sua importância para a história da educação das mulheres no Brasil.

Para se ter uma idéia da formação oportunizada, no jornal de dezembro de 1956 constam os cursos oferecidos pelo colégio:

Curso Primário e Admissão. Curso Secundário - ginásio e científico. Curso Secretariado- 3 anos, desde 1952, preparo especializado para o exercício da função de secretária. Curso de Formação professores primários. Curso de Economia do Lar - modelado nos mais modernos cursos similares dos EUA. Prepara e orienta moças para o exercício de funções relevantes quer seja no lar, quer em ocupações profissionais de grande procura na atualidade. (O Crisol, dez., 1956, n. 2, p. 7)

Com relação à história da educação das mulheres, importa dizer que, desde o final do século 19, a educação revelou-se uma necessidade tendo em vista o processo de modernização e urbanização da sociedade brasileira. A grande justificativa era preparar as mulheres para exercer a "função social de educadora dos filhos, ou, na linguagem republicana, na função de formadora dos futuros cidadãos" (Louro, 2004, p. 447). Na década de 1950, embora ainda se valorizasse a formação da mulher considerando seu destino de mãe e esposa, a escola anunciava outras perspectivas ao promover o acesso à formação profissional, especialmente desenvolvida no Curso de Secretariado Normal.

Interessa analisar em números as matrículas do Colégio Americano. Em 1956, O Crisol divulga essas informações. Nota-se um número elevado de alunas no Curso Secretariado, nitidamente profissionalizante, mais que o dobro daquelas que cursavam Economia do Lar. O Curso Normal era aquele que reunia a maior quantidade de alunas, fato esperado, considerando o processo de feminização do magistério que se consolidava naquele tempo:

Primário - 344.

Ginásio - 405.

Científico - 48.

Secretariado - 48.

Economia do Lar - 22.

Dietética - 8.

Normal - 59. (O Crisol, 1956, n. 1, p. 2)

Como estratégia de valorização do Curso de Secretariado, o jornal de 1955 mostra uma foto das formandas seguida das frases "Em cima aparecem três das cinco novas secretárias. As que pretendem trabalhar já estão colocadas." (O Crisol, out., 1955, n. 2, p.

\footnotetext{
${ }^{7}$ Informações consultadas no site da escola: www.metodistasul.edu.br/colegio_americano.
} 
6). O texto anuncia a efetividade da profissionalização, pois a formação recebida na escola já as encaminhava para o mundo do trabalho, entretanto, pelas palavras utilizadas percebe-se que seguir a profissão não era uma regra e sim uma possibilidade.

É possível que houvesse um desconhecimento geral acerca do Curso de Economia do Lar. Assim, em 1960, foi publicada uma explicação de suas especificidades:

Geralmente toda a moça sonha em ter um lar, filhos, uma vida feliz e segura. Mas para isso precisa ter noção do cuidado de uma casa. Temos aqui no CA um curso modelar servido por professores com larga competência num ambiente todo especial para este tipo de curso. Nós formamos em três anos de estudo, estando então preparadas para realizar nosso sonho ou então lecionarmos Trabalhos Manuais e Economia Doméstica em outros ginásios oficializados. Puericultura - visitas a orfanatos. Enfermagem - visita a Santa Casa. Alimentação - o terceiro ano demonstra pratos especiais. Costura - desde o enxoval do bebê até roupas para homem. Português, Química, Psicologia, Sociologia, decoração do lar, economia e direção do lar, relações familiares, dietética da nutrição, contabilidade, apreciação musical. Tirem o curso de economia e sejam felizes em seus lares. (O Crisol, nov., 1960, n. 3, p. 3)

O Curso legitimava o papel de dona de casa, endossando a relevância do estudo para formação científica de boas mães e donas de casa. $O$ currículo enfatizava a organização doméstica, trabalhos manuais, noções de enfermagem, entre outros saberes considerados úteis para uma mulher gerir o seu lar. Portanto, os objetivos do curso sinalizam para a importância de uma mulher capacitada pelos saberes da escola que, dessa forma, pode dar conta das demandas próprias da administração de um lar e da criação de filhos. Além disso, existia a possibilidade de profissionalização, especialmente pelo exercício do magistério.

O pioneirismo do Colégio Americano em relação à formação das mulheres também foi evidente no Curso de Dietista, provavelmente pouco conhecido da população. O Crisol de 1952 promove a sua divulgação pela notícia Como nasceu o Curso de Dietista no Colégio Americano. Explica a duração de dois anos do curso e seu objetivo de formar técnicos em alimentação "a quem está reservado um grande papel na política alimentar do Brasil." O texto prossegue com mais informações:

A profissão de dietista é nova, porém assume grande importância. É um curso técnico, especializado e de base científica dotado de aplicabilidade prática, através de ensino técnico e trabalhos práticos aplicados à ciência alimentar nos hospitais, refeitórios populares, pensionatos, dietética infantil, creches e lactários. (O Crisol, set., 1952, n. 2, p. 7)

O Colégio Americano tem sua história atrelada às mulheres e foi assim que se destacou no contexto educacional dos anos 1950 e 1960. Ao reconhecer o valor da formação educacional das mulheres, foi muito além do Curso Normal e oportunizou às moças outras perspectivas de vida, incluindo o acesso a diferentes formas de profissionalização, legitimadas pela escola e pela sociedade. 


\section{O Crisol}

Os textos produzidos para O Crisol revelam olhares sobre o mundo. Entende-se que o jornal cumpria seu papel formativo, promovia aprendizagens de determinados discursos, ensinava modos de ser, com vistas a educar e moralizar o leitor. Ao longo das páginas vêse que os discursos adquirem significados de muitas formas, inclusive pelos procedimentos tipográficos e de ilustração de cada exemplar analisado. A ênfase em certos temas, a linguagem utilizada e a natureza do conteúdo não se dissociam das leitoras que o periódico pretendia atingir.

Pensando na materialidade do acervo e seus suportes, importa dizer que se assemelhava aos jornais diários da época. Suas folhas medem em torno de $52 \mathrm{~cm}$ de altura e $30 \mathrm{~cm}$ de largura, o que permite um bom aproveitamento do espaço. Eram poucas páginas, entre 8 a 10, em formato longo e verticalizado, sendo ocupado, em geral, por três colunas de escritos. Na capa, bem acima, observa-se uma espécie de logotipo, em que o desenho mostra um livro aberto e no meio uma tocha acesa que simboliza, talvez, a luz que ilumina o conhecimento. A seguir, uma manchete, às vezes em letras maiores, às vezes menores, talvez conforme a importância atribuída à notícia. Normalmente, essa manchete trazia algum fato entendido como marcante para a comunidade escolar.

Poucas são as imagens, reservadas a ocasiões comemorativas, especialmente formaturas. Nota-se uma preocupação em preencher todos os espaços com letras miúdas, provavelmente as questões de custos para publicação influenciavam diretamente em sua confecção. Entre cada informe, a divisão é feita por um traço horizontal e deixavase pouco espaço entre uma notícia e outra. De um modo geral, eram poucas as propagandas, embora a quantidade tenha aumentado no final da década de 1950. Não há nada colorido. Costumeiramente usa-se o negrito para destaque a algumas frases. Em geral, foram encontradas duas ou três edições anuais, mas há situações de um único exemplar por ano. Todas essas impressões geram práticas diversas de leitura. Segundo Burke (2008) "a aparência física da página impressa funciona como uma série de deixas para os leitores, encorajando-os a interpretar o texto de uma maneira e não de outra" ( $p$. 91). 
Figura 1

A primeira página de uma das edições do periódico O Crisol.

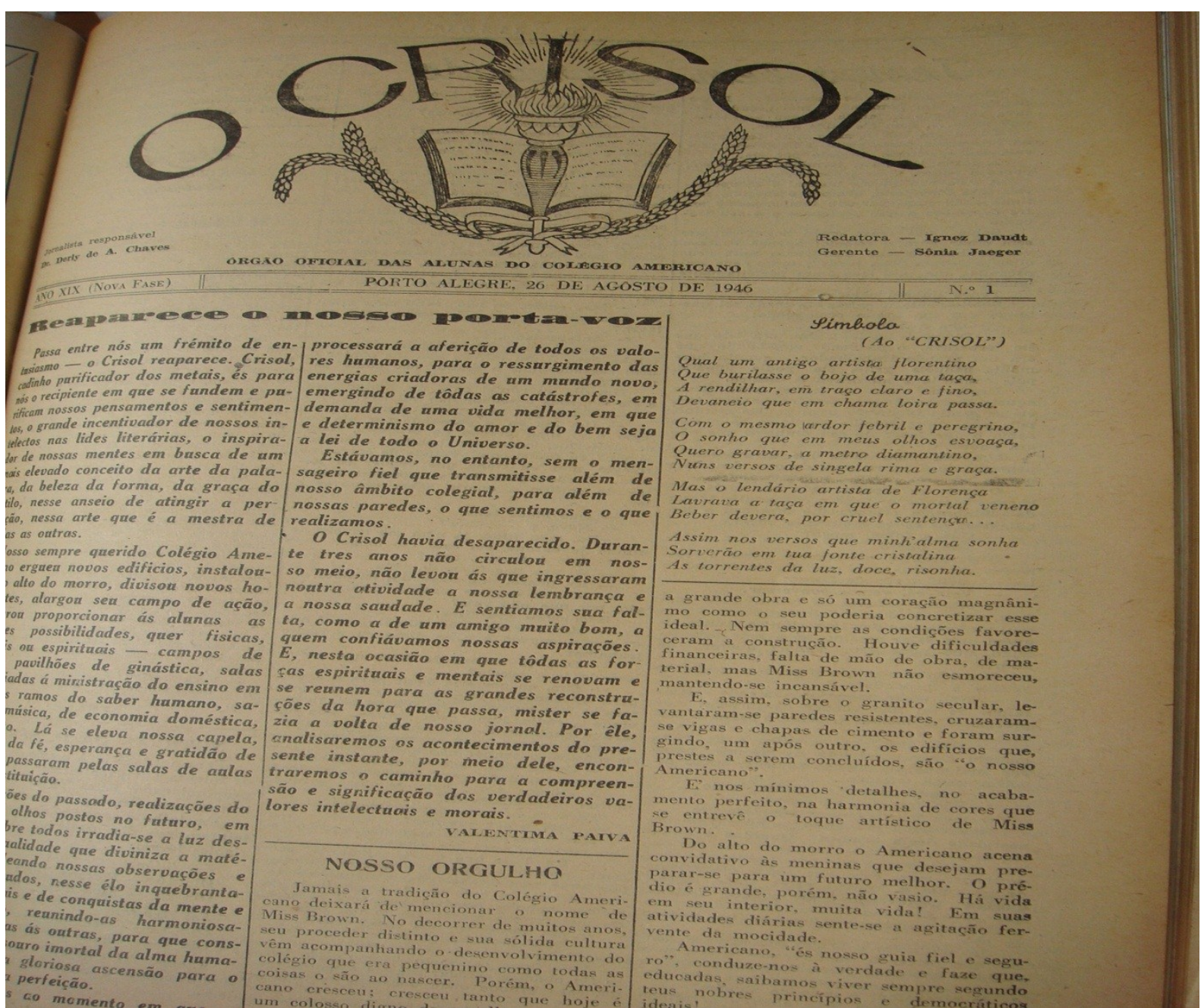

Fonte: O Crisol, capa da edição n. 1, agosto de 1946. Memorial do Colégio Americano, Porto Alegre/RS.

A seguir, apresenta-se uma tabela com os títulos em destaque de cada edição analisada.

\section{Quadro 1}

Títulos dos editoriais analisados do jornal O Crisol.

\begin{tabular}{|l|l|}
\hline \multicolumn{2}{|c|}{ O Crisol - Americano } \\
\hline \multicolumn{1}{|c|}{ Formato: Jornal - 35 edições (1946-1964) } \\
\hline Ano.1946 - n. 1 & Manchete \\
\hline Set./out.1946 - n. 2 e 3 & Reaparece o nosso porta-voz. \\
\hline Nov. 1946 - n. 4 & Nossa Cape Cansinar a viver - lema. \\
\hline Dez. 1946 - n. 5 & Crônica sobre os momentos passados no Colégio Americano. \\
\hline Jun. 1947 - n. 6 & $\begin{array}{l}\text { O jornal, fundado em 1923, sempre "mereceu carinho e } \\
\text { interesse de todos". }\end{array}$ \\
\hline
\end{tabular}




\begin{tabular}{|c|c|}
\hline Jul. 1947 - n. 6 & Mocidade - instrução e educação. \\
\hline Ago, set. 1947 - n. 6 & Personalidade. \\
\hline Out./Nov.1947-n. 7 e 8 & Juventude eterna do Colégio Americano. \\
\hline Jun. $1952-\mathrm{n} .1$ & Crisol. Informe sobre o retorno do jornal. \\
\hline Set.1952 - n. 2 & $\begin{array}{l}\text { Mais uma realização. Reportagem sobre a construção da } \\
\text { piscina. }\end{array}$ \\
\hline Out.1952 - n. 3 & Colégio Americano. Histórico do colégio com fotos. \\
\hline Jun.1953-n. 1 & A nossa Piscina. \\
\hline Set.1953 - n. 2 & O significado da semana da pátria. \\
\hline Out.1953-n. 3 & $\begin{array}{l}\text { Evocando o passado. Fotos do Colégio e lembranças de } \\
\text { Carmen Chacon. }\end{array}$ \\
\hline Jun.1954 - n. 1 & A alma do Americano. \\
\hline Out.1955 - n. 2 & Colégio Americano, benfeitor da juventude. \\
\hline Jun.1956 - n. 1 & Recordar é viver. \\
\hline Dez.1956-n. 2 & Oh, querido Americano! Transcrição do hino do colégio. \\
\hline Jun.1957 - n. 1 & Retrato de mãe. \\
\hline Set. 1957-n. 2 & Se... Inspirado em Rudyard Kipling. \\
\hline Dez.1957-n. 3 & Um adeus que se repete. \\
\hline Out.1958-n. 9 & Campanha pró construção do prédio primário. \\
\hline Dez.1959 - n. 1 & Este é o dia que o senhor fez! \\
\hline Mai.1960 - n. 1 & Educar é ensinar a viver. Poema sobre o colégio. \\
\hline Out.1960 - n. 2 & Colégio Americano Festeja seu $75^{\circ}$ aniversário. \\
\hline Nov.1960 - n. 3 & Rede nacional da legalidade. \\
\hline Out. $1961-\mathrm{n} .1$ & Ao Colégio Americano. \\
\hline Nov.1961 - n. 2 & O Crisol. Artigo sobre o nome do jornal. \\
\hline Maio $1962-\mathrm{n} .1$ & Vida de Carmen Chacon. \\
\hline Ago.1962 - n. 2 & O Brasil, bi campeão na copa do mundo. \\
\hline Set.1962-n. 3 & Despedida/Teu aniversário. \\
\hline Out.1963- n. 2 & $\begin{array}{l}\text { Explicação do porque esta edição está diferente (datilografada } \\
\text { e mimeografada). }\end{array}$ \\
\hline Jun.1964 - n. 1 & O IV centenário de Shakespeare. \\
\hline Nov.1964 - n. 4 & Felicidades formandas! Obrigada". \\
\hline
\end{tabular}

Entendendo que as folhas impressas são fontes privilegiadas para a apreensão do imaginário local, esses títulos, via de regra, explicitam e reverenciam a instituição. Muitas delas apresentam referências à história da escola, especialmente à fundadora Carmem Chacon. Parece que era importante essa divulgação para que as novas gerações não esquecessem o papel da jovem uruguaia e sua forte relação com a criação da escola. Sua trajetória, de certa forma, corrobora a instituição que se ocupava essencialmente da educação de moças.

O jornal assume a posição de informar e divulgar as iniciativas do colégio, é um instrumento de propaganda, entretanto, há momentos em que se nota algumas vozes de resistência. Parece que se publicava aquilo que era de interesse da instituição e que, portanto, colaborava para forjar uma imagem positiva entre as leitoras. As alunas que assumiam a tarefa de organizar o jornal se apropriavam desses discursos. Nesse sentido, o que acontecia dentro dos limites da escola era divulgado, como a construção da piscina, 
da capela, os aniversários da escola, as formaturas, atividades sociais, encontro de exalunas e a história do jornal.

$\mathrm{O}$ fato de ter uma parcela das alunas internas repercutia nas páginas do periódico. $\mathrm{O}$ internato promove certo recolhimento, uma espécie de enclausuramento em que moças permaneciam um tanto alheias aos acontecimentos externos, fixando seus olhares para o cotidiano escolar. Talvez por isso O Crisol pouco dialogasse com o que acontecia fora dos muros da escola.

Em outubro de 1961 o periódico evidencia um dos raros momentos em que a capa mostra um tema político, uma notícia sobre a Campanha da Legalidade, tema ainda hoje presente no imaginário dos rio-grandenses. Não por acaso, no título, as letras aparecem pequenas, sem negrito, contrastando, por exemplo, com as manchetes das edições de setembro de 1952, Mais uma realização, e de junho de 1953, A nossa piscina, que relatam o mesmo fato. Letras grandes, fotografia que ocupa meia página e textos descritivos no restante das páginas evidenciam que para assuntos da casa todo o destaque; para temas de ordem política, discrição e brevidade na exposição.

Figura 2

O tema da Legalidade em uma das edições de O Crisol.

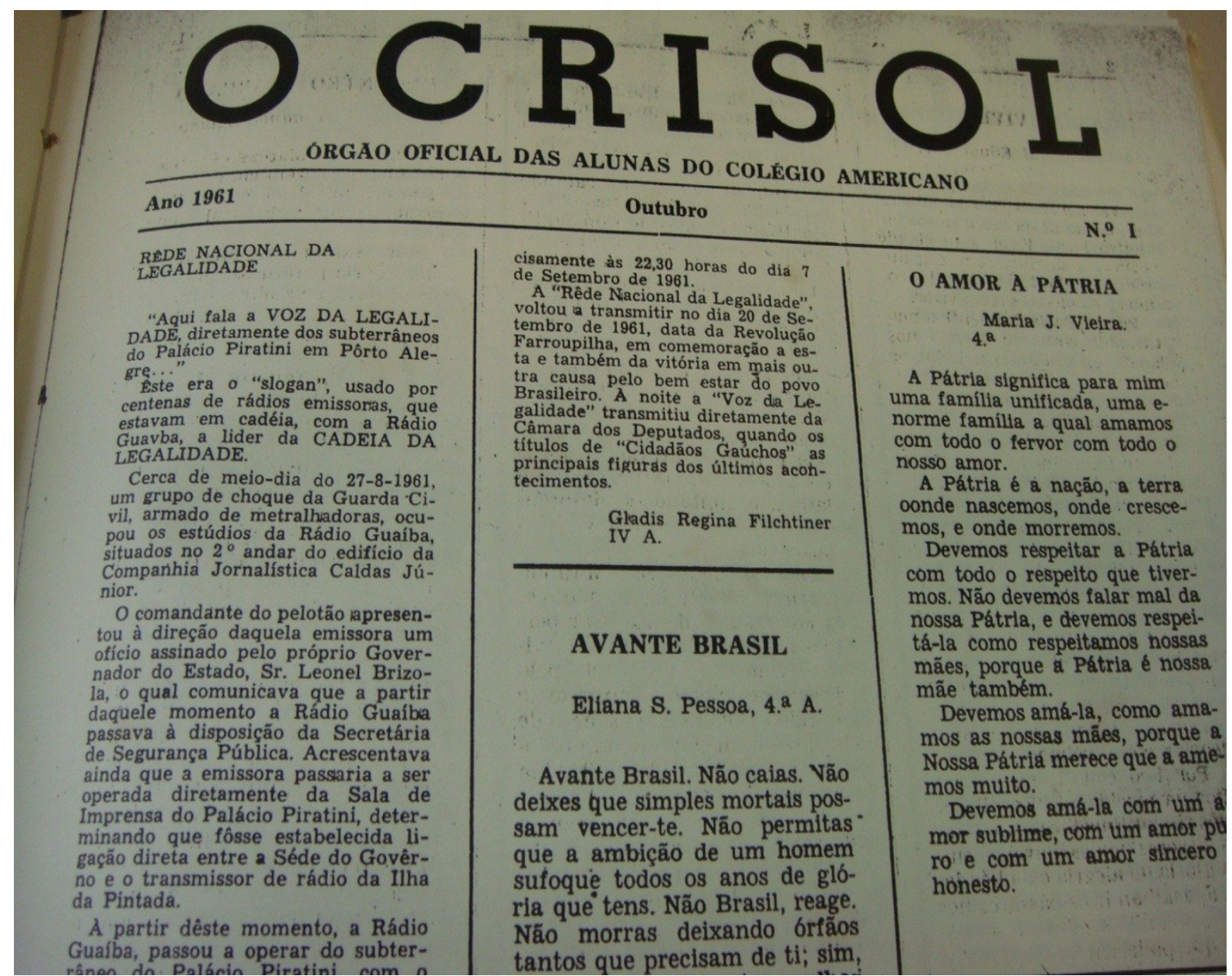

Fonte: O Crisol, capa da edição n.1, outubro de 1961, Memorial do Colégio Americano, Porto Alegre/RS. 


\section{Figura 3}

A construção de uma piscina na escola é notícia em O Crisol.

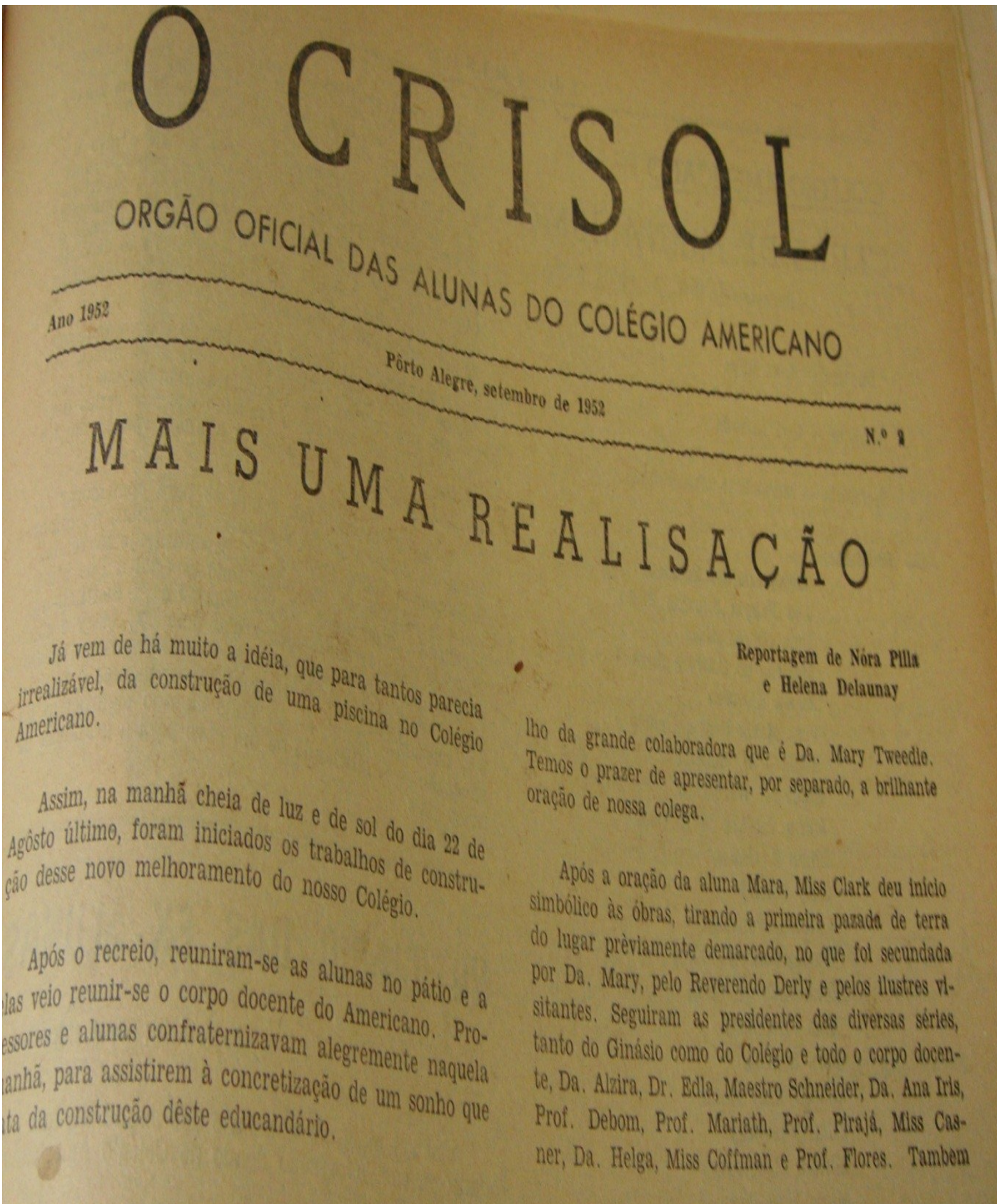

Fonte: O Crisol, capa da edição n. 2, setembro de 1952, Memorial do Colégio Americano, Porto Alegre/RS. 
Figura 4

A construção de uma piscina na escola é notícia em O Crisol.

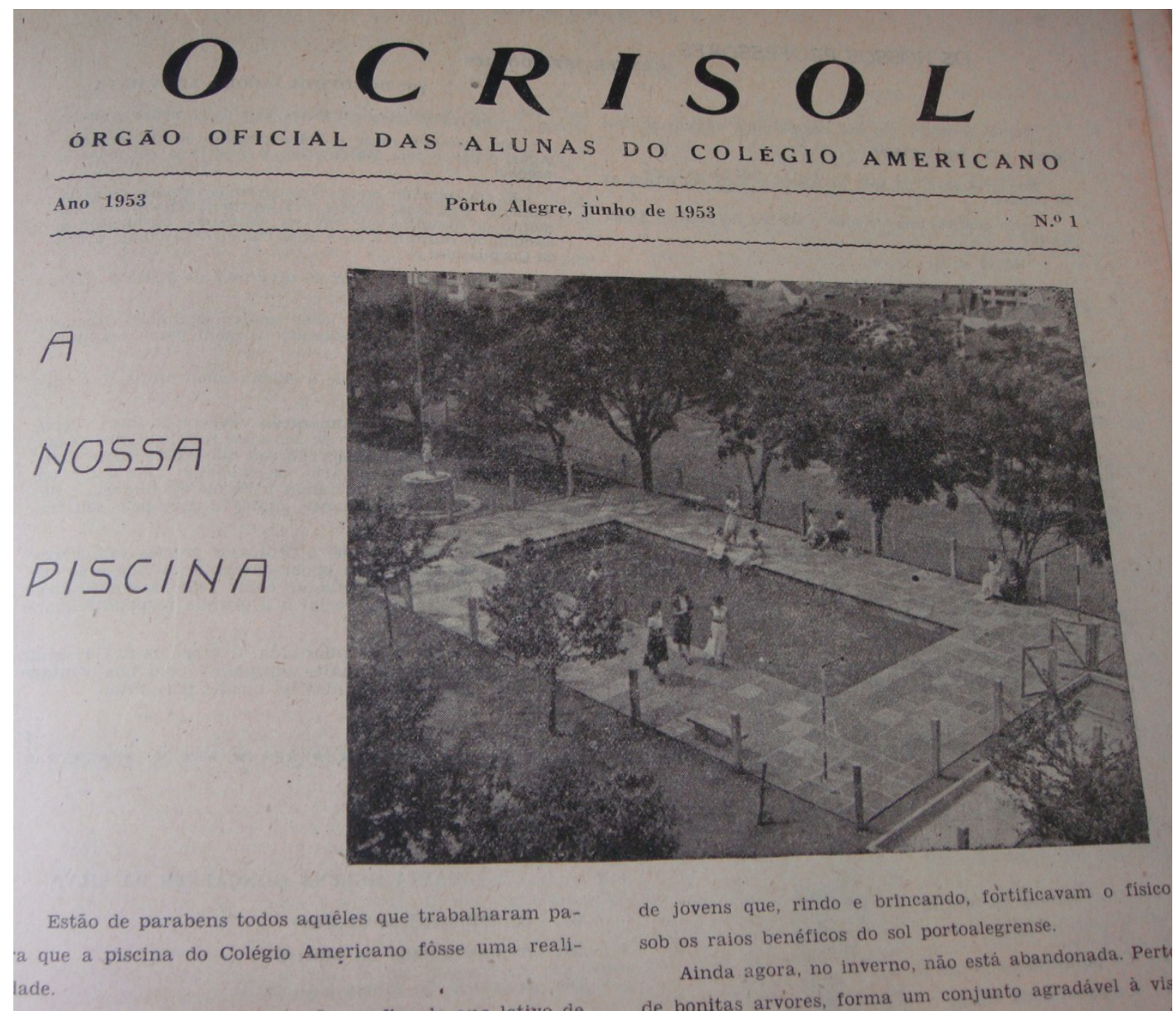

Fonte: O Crisol, capa da edição n. 1, junho de 1953, Memorial do Colégio Americano, Porto Alegre/RS.

De um modo geral, percebe-se que as autoras evitam emitir opiniões próprias sobre qualquer assunto. O estilo da narrativa, via de regra, assume o tom da descrição; quem escrevia preocupava-se em relatar em minúcias o acontecimento, sem uma tomada de posição. Os textos apresentam relatos detalhados de várias atividades que compunham o cotidiano escolar e divulgam saberes e práticas realizadas no espaço da instituição escolar. Um exemplo da escrita do jornal é este:

Uma visita à Escola Técnica Senador Ernesto Dornelles

Atendendo ao gentil convite que nos foi enviado, comparecemos à reunião realizado na Escola Técnica Senador Ernesto Dornelles. [...] Fomos recebidas pelas moças componentes do grêmio da escola e logo em seguida fomos incorporadas a um dos diversos grupos que fariam a visita às instalações do estabelecimento. Começamos a interessante visita pelo 
Curso Industrial de 4 anos onde as alunas passam por diversas oficinas para que possam escolher aquelas nas quais irão se especializar. $\mathrm{Na}$ primeira oficina, de bordados, apreciamos os finos trabalhos de filé, frivolites, bilros, todos feitos pelas alunas; na sala "corte e costura" vimos confecções feitas inteiramente à mão, com muita perfeição e bom gosto. $\mathrm{Na}$ oficina de chapéus, nos foram mostrados modelos muito bem executados e nos admiramos ao saber que tinham sido feitos pelas alunas com moldes imaginados por elas mesmas. Visitamos o auditório onde as alunas estavam ensaiando números para a Semana da Pátria. Em seguida, travamos conhecimento com o curso técnico que é de três anos e é equiparado ao Curso Colegial [...] $\mathrm{Na}$ oficina de trabalhos em couro, admiramos objetos tais como pastas, cofres, capas para livros, carteiras, todos com lindos desenhos pintados ou gravados. [...] Após a visita foram oferecidos aos presentes refrescos e salgadinhos enquanto todos conversavam com animação. (Helena Dagnino, O Crisol, set., 1953, p. 3)

A produção de O Crisol fazia parte das atividades do Clube do Jornalismo, dirigido pelo professor João do Prado Flores, que parece ter sido uma figura notável na história do Colégio Americano. Em 1950, assim é publicado:

O jornal das alunas do colégio deve ser uma expressão das atividades de todos os cursos e oportunidade para revelar capacidades e valores em formação. Esperamos desse modo contar com a simpatia, interesse e colaboração de todas as alunas do Colégio Americano. (O Crisol, maio, 1960, p. 5).

\section{Escritos de moças, mas tendo a coordenação de um homem, assim configurava-se O Crisol.}

Em 1923, as alunas iniciaram um Clube de Jornalismo e com ele teve início a publicação do jornal escolar, com o objetivo de ser o veículo de comunicação da comunidade escolar e o "mensageiro fiel para transmitir seus sentimentos" ( $O$ Crisol, n. 1, 1946, p. 1) além dos muros escolares. Tinha também a intenção de expor as criações literárias e as particularidades da vida escolar das alunas. Em 1927 saiu de circulação e retornou em 1946, com cinco edições. O nome foi escolhido pelas fundadoras por significar "cadinho onde se apuram os sentimentos, aquilo que serve para patentear as boas qualidades do indivíduo" (O Crisol, 1952, p. 2).

Em outubro de 1960 os editores explicam que O Crisol tem origem grega do nome khryssos, vaso onde se fundem metais:

Como no crisol se derretem os metais purificando-os veio por metonímia a purificação dos costumes e a obtenção de boas qualidades também chamar-se crisol. Talvez nascesse dessa ideia a razão de ter sido batizado o nosso jornal com o nome tão expressivo e simbólico Crisol. Ora neste colégio onde se depuram tantos caracteres justifica-se a existência de um crisol comum a todas as alunas. (O Crisol, out., 1960, n. 2, p. 5)

As metáforas presentes no nome do jornal indicam os valores apregoados pelo Colégio: o espaço em que as moças se escolarizavam, purificavam e desenvolviam seus predicados de acordo com a moral cristã vigente. Moças que passavam por uma 
formação que ia além dos saberes da escola: eram moldadas pelos valores burgueses da modernidade para serem mães, esposas e, até mesmo, profissionais.

Miss Brown, diretora do colégio nos anos 1940, a mãe espiritual, avalia o significado do periódico:

O Crisol desde a sua fundação em 1923 mereceu o carinho e o interesse de todos, professores e alunas e tem sido para o nosso colégio o revelador do espírito leal e ativo de suas alunas, apresentando os seus pensamentos e ensaios literários, enquanto elas procuram melhorar e aperfeiçoar sua habilidade na arte de expressar-se. (O Crisol, set./out., 1946, n. 2-3, p. 1)

Uma Carta aberta às colegas que ficam, da edição de dezembro de 1959, nos mostra as responsabilidades que havia na produção de $\mathrm{O}$ Crisol:

\begin{abstract}
Querida colega,
Esta carta é dedicada a ti americanista que continuarás estudando em nosso colégio nos próximos anos. Queremos que nosso jornal possa ter real valor em tua vida que ele não seja um simples aglomerado de palavras, mas um inspirador, um guia para que possas tirar proveito, possas entender o verdadeiro sentido das palavras. Nos próximos anos, serás tu quem organizarás o jornal. Tu correrás em busca de artigos, tu procurarás uma tipografia não muito cara, tu revisarás os artigos e farás a paginação. Então conhecerás o verdadeiro sentido da palavra colaboração. Verás a hesitação daquelas que tem um trabalho a oferecer mas se sentem temerosas de que seu trabalho não seja bom. (As editoras, Vera Kirst e Aline Peng, O Crisol, dez., 1959, n. 1, p. 10)
\end{abstract}

O texto evidencia o envolvimento das alunas com o periódico. Era um trabalho artesanal, que exigia fôlego e dedicação: as alunas precisavam procurar notícias, mobilizar as outras colegas para que participassem. Além disso, as questões financeiras, provavelmente, também eram importantes, bem como a busca por propagandas, preocupação com a economia, revisão dos artigos e estímulo às colegas que continuariam a tarefa de fazer o jornal.

De um modo geral, não há propriamente seções, são títulos que ora se repetem, ora desaparecem. As autoras preocupam-se em divulgar o que acontecia dentro dos limites do colégio. Valorizava-se, também, saídas para estudo e as viagens, que são relatadas com riqueza de detalhes. As entrevistas com alunas e professores, chamadas Entrevista de minuto ou Entrevista de segundo, alternadamente, aparecem em várias edições e pretendiam dar a conhecer um pouco mais sobre as colegas. Os temas ligados à religiosidade e à exaltação ao colégio como sendo o alicerce de uma vida plena estão presentes em muitas edições, principalmente nas redações feitas pelas alunas no ano de formaturas. Nos exemplares consultados há pequenas alterações na passagem dos anos 1940 para 1950. 
Quadro 2

Seções do periódico O Crisol.

\begin{tabular}{|l|l|}
\hline \multicolumn{1}{|c|}{ Anos 1940 } & \multicolumn{1}{c|}{ Anos 1950 e 1960 } \\
\hline Ração Espiritual. & Conselhos do DOE (Departamento de \\
Sociais. & Orientação Educacional). \\
Sorrisos no internato (ingenuidades). & Noticiário das ex-alunas. \\
Responda se puder. & Excursão a Santa Cruz, São Leopoldo. \\
Você sabia que. & Viagem a Buenos Aires \\
Anchieta, o escritor. & Mãe. \\
Aniversários. & O que se passa pelo 3 B? \\
Aula de cortesia. & O que o Americano nos legou? \\
O aniversário do Americano. & Uma visita a uma editora, ao Colégio \\
Escreve uma ex-aluna. & Anchieta, à maternidade Mario Totta... \\
Revelações poéticas do Americano. & Os nossos professores. \\
Traços gerais da excursão ao Rio. & Entrevista do mês. \\
O que vai pelo 62? & Perfil de um colega. \\
Dia das mães. & Relembrando o passado. \\
Entrevista de segundo. & Semana da ênfase religiosa. \\
Entrevista de minuto. & \\
Meditação em crepúsculo. & \\
Divagando. & \\
\hline
\end{tabular}

\section{Um jornal para mulheres}

Os escritos dos jornais nos instigam a perceber diversos aspectos das identidades femininas e das práticas educativas daqueles tempos. Segundo Fischer (2004), os periódicos influenciam o processo de subjetivação dos leitores. As práticas discursivas que se apresentam nos textos consultados "ajudam a constituir o próprio objeto de que falam" (p. 325), aquelas moças estudantes da escola, algumas internas, outras não, alunas de diferentes cursos, algumas buscando uma profissionalização, outras não, todas vivendo os anos 1950 e 1960 no Brasil, época de mudanças no estatuto das mulheres.

A partir do século 19, especialmente, as mulheres cada vez mais "se inserem em diversas manifestações do escrito" (Gonçalves, 2006, p. 101) e os textos produzidos por elas começam a circular entre um número cada vez maior de leitores e a exercer alguma influência sobre as esferas de sua atuação. O Crisol constituía-se em um espaço ocupado pelas mulheres e por seus escritos, neste caso, pode-se dizer que a escola promoveu essa possibilidade ao viabilizar a produção do periódico.

A temporalidade que se inscreve este estudo são os anos 1940 a 1960. Economicamente o Brasil vivia um período de crescimento industrial e urbano nunca antes experimentado. Otimismo, esperança no progresso e busca pelo desenvolvimento são características desse período, marcado pela ascensão da classe média. Neste contexto, aumentaram-se as possibilidades educacionais e profissionais para homens e também para as mulheres: 
Este é o dia que o Senhor. Regozigemo-nos e alegremo-nos nele". Na história da humanidade, nenhuma época oferece tantas oportunidades para tantas pessoas como hoje. No passado, as escolas eram poucas e para um grupo privilegiado. Hoje, as escolas existem e oferecem oportunidades para as massas. Nos países onde existe democracia, a vida do indivíduo tem valor. O bem estar do povo torna-se a riqueza do país. Pois muitos governos do mundo estão hoje se esforçando para dar todo apoio possível ao povo. O Senhor nos disse que o mundo está cheio de oportunidades. Aproveitando as oportunidades tornamo-nos vitoriosos em vida. Ele afirmou que sempre estará conosco nos guiando, inspirando. ( $O$ Crisol, dez., 1959, n. 1, p. 5)

Os anos 1950 e 1960 foram tempos melhores para as mulheres, especialmente para aquelas oriundas da classe média, pois, em seu horizonte de vida estava a escolarização e, quem sabe, a profissionalização. Não obstante, as distinções entre papéis sociais masculinos e femininos continuaram a estabelecer lugares de sujeito próprios a homens e mulheres. A moral sexual diferenciada continuava forte e o trabalho da mulher, ainda que cada vez mais comum, era cercado de preconceitos, tendo um caráter subsidiário aos labores masculinos. Estes continuavam na posição de provedores do lar (Bassanezi, 2004).

Mas é nesse tempo que podem ser observados uma "infinitude de pequenos deslocamentos" (Rancière, 1995, p. 48) em relação aos espaços ocupados pela mulher na sociedade. Segundo o autor, "o que conta não é saber se as mulheres ocupam mais ou menos espaço, mas qual é a natureza do espaço que elas podem ocupar, a natureza dos títulos de ocupação desse espaço" (lbid., p. 46)

Os discursos evidenciam as condições de fragilidade desse momento da história das mulheres. Por um lado, insiste-se no casamento, na grandeza da maternidade, na vida familiar pautada no exercício dos papéis de mãe zelosa e esposa dedicada. Por outro, notam-se vozes dissonantes, como uma espécie de resistência a aquilo que, durante muito tempo, estava prescrito para as mulheres. Campos (2009), ao comparar os jornais a uma arena, considera que "o discurso jornalístico jamais transita em um mar de rosas do curso retilíneo dos fatos noticiados, na subversão mostra-se o avesso do sistema dominante de representação" (p. 31).

Um bom exemplo do que se está falando aparece na seção Noticiário das ex-alunas, ao lado das notas referentes a contratos de casamento, casamentos, nascimentos, viagens ao exterior, as alunas destacam os nomes das colegas que continuavam a estudar depois de deixar a escola e os nomes daquelas que concluíram um curso superior. Assim, podemos ter uma idéia sobre o futuro daquelas moças. Em 1955, por exemplo, ao lado dos informes de casamentos, noticiavam-se as formaturas de cursos em nível superior.

Na Pontifícia Universidade Católica uma ex-aluna formou-se em Jornalismo e na Universidade Federal do Rio Grande do Sul duas concluíram o curso de Medicina, duas formaram-se em História Natural e em Farmácia. Além disso, três moças foram contempladas com bolsas de estudo nos Estados Unidos. Em 1959, novamente encontram-se nomes das formandas em cursos superiores: Medicina (três), Educação Física (uma), Geografia (uma), Letras Neo-Latinas (três), História Natural (uma) e 
Pedagogia (uma). Pode-se pensar que sejam pouco expressivos esses números, mas eles são muito importantes por sinalizarem mudanças no destino delas.

Entretanto, permanece a dúvida em relação à profissionalização de fato dessas mulheres: conseguiram exercer a profissão para a qual se prepararam? De qualquer forma, parece que às alunas responsáveis pelo jornal importava informar esses acontecimentos à comunidade leitora e assim manifestar sua valorização às trajetórias das ex-alunas.

As vozes dissonantes não se calam. Em uma fala da candidata ao título de Rainha Estudantil, a moça diz: "a mulher deve seguir sua profissão, deve ter independência econômica e espiritual" (1952, n. 3). Resta mais uma pergunta: e quem lia essas notícias, como se sentia? Qual discurso interpelava mais, o do casamento ou aquele que anunciava uma possibilidade de construir um futuro distinto dos padrões sociais até então vigentes na sociedade?

No final do ano de 1957, ao lado da foto que mostra as formandas do Curso Científico, o texto instiga a pensar: "Estas moças concluíram o curso científico. Os rostos sorridentes revelam que tudo foi bem no fim do ano. Que virá depois? Vestibulares? Curso superior ou a caminho do altar? Esse é o segredo que nem depois elas contam." ( $O$ Crisol, set., 1957, n. 2, p. 4). Parece-me que o fato delas citarem como alternativa a continuidade dos estudos é um indicativo de pequenos deslocamentos, embora a vida profissional não tenha sido mencionada como perspectiva de futuro.

As frases mais comuns no transcorrer das edições reforçam e naturalizam o destino das mulheres atrelado ao casamento e maternidade: "Nada se compara ao amor materno"; "A felicidade é algo que desejamos muito" (O Crisol, 1958, n. 9, p. 5); "Não hesite em cumprir o mais sublime e sagrado dever da mulher: a maternidade" ( $O$ Crisol, 1952, n. 3, p. 2). A seção O cantinho do lar evidencia a importância da formação para o lar ao oferecer às leitoras orientações em relação à vida doméstica, tais como "o segredo da maionese", "algumas das 1001 aplicações do bombril", ou ainda "você sabia que..." "a gelatina em pó ao contrário da de em folhas deve ser dissolvida em água fria?" ( $O$ Crisol, set., 1956, p. 3).

Vozes masculinas também se fazem presentes no jornal. Destaca-se a seção Os nossos professores e a entrevista com prof. Jacob, de Física. Ao ser indagado sobre as futuras profissões das alunas do Colégio Americano, responde:

A Medicina não serve para uma moça que pretenda casar porque a senhora casada é antes de mais nada mãe e esposa e a Medicina não permite horário fixo. Outras profissões como arquitetura até são recomendáveis como ocupação para seu tempo livre desde que não sejam levadas ao extremo. (O Crisol, out., 1952, n. 3, p. 6)

Na seção O que eles criticam (1952, maio), a reportagem apresenta os resultados de uma entrevista com homens, em que se indaga sobre o que consideravam digno de censura na mulher. Quanto ao seu aspecto físico, um deles diz: "Quando vejo uma bolsa cheia de objetos e coisinhas inúteis sempre me vem à memória uma pessoa mal cuidada e dona de casa incompetente." Outra resposta no mesmo sentido é: "Odeio ver uma mulher procurando um lenço ou um batom numa carteira sobrecarregada e que 
finalmente o traz de mistura com papeizinhos, retratinhos, pente, etc." (p. 3). Permanece a indagação, por que um jornal produzido e lido por moças preocupava-se em apresentar essas impressões masculinas? Ao ler esses textos, as moças deveriam se curvar a um modelo de dignidade estabelecido por eles?

Nos anos 1940 a seção Ração espiritual talvez fosse aquela que melhor cumprisse o papel de construção de civilidades ao transmitir reflexões religiosas e, ao mesmo tempo, prescrever modos de ser próprios a uma determinada conduta considerada apropriada às alunas da escola. A seção fala sobre perseverança, escolhas da vida: "Quem escolhe o caminho a seguir é a própria moça que tem também a possibilidade de mudar seu caminho se assim desejar" (1946, n. 1, p. 3); "Deus sempre acompanha"; "o amor nunca falha" (1947, n. 6, p. 2) são frases que evidenciam a crença no poder do amor para enfrentar os momentos de dificuldade. "Pense nas coisas positivas" é uma das orientações para agir com confiança nos "desígnios de Deus" (1947, n. 7, p. 2).

O tempo passou, as moças mudaram. Neste aspecto, a narrativa de Miss Clark, diretora da escola no final dos anos 1940, de certa forma sintetiza essas mudanças que se manifestavam no comportamento das alunas. Ao avaliar a história do Colégio Americano, disse ao Crisol: "O colégio era na Avenida Independência, pequeno com menos de 300 alunas. O colégio sempre liderou inovações. Quanto às alunas, bem... há vinte e cinco anos não havia tantas atividades fora do colégio" (1960, maio, p. 4).

É assim que nos anos 1950 observam-se algumas modificações no periódico: aparecem mais ilustrações, algumas propagandas, mais informações sobre as próprias alunas. Da mesma forma é no período dos anos 1950 que a valorização das sociabilidades aburguesadas, das regras como bem comportar-se, marcadas por conselhos de boa conduta, são mais evidentes a cada página. Ou seja, os preceitos de civilidade, de vida saudável, de governo de si passam a se fazer presentes em diferentes seções e oferecem recomendações, especificações de procedimentos a adotar.

Nos anos 1950 desaparece a seção Ração espiritual e os informes do Departamento de Orientação Educacional, na seção intitulada Conselhos do DOE, assumem um papel de orientação por meio de conselhos que versavam sobre leis para ter boa saúde, bom trabalho, por exemplo. As práticas de higienismo também são manifestas no cuidado com aparência, com as roupas limpas, bem passadas. A atitude mental é considerada fator de sucesso para os estudos: a aluna não deve tentar superar as colegas, mas a si mesma. Um conselho: "Estude com método e colherá melhores resultados".

Talvez ao longo de toda a pesquisa realizada, o mais emblemático em termos de preceitos de civilidade sejam essas duas listas, denominadas Atitudes da boa aluna e as Resoluções para o bom cristão, publicadas no jornal de 1955:

Atitudes da boa aluna.

Ouve as críticas que trarão proveito para si e para os colegas.

Desiste de suas preferências próprias quando isto tem benefício para o bem do grupo.

Respeita direitos e propriedades dos outros.

Tem o espírito de um estudante.

Está sempre pronta, bem preparada e ansiosa por trabalhar.

Obedece todas as leis e regras do colégio.

Sabe admitir erros quando é advertida por estar errada. 
Cumpre fielmente promessas e deveres.

Merece a confiança do professor sem que ele precise estar vigilante.

Sabe a razão pela qual frequenta o colégio

É cortês para com professores e colegas.

É grata por todos os favores e serviços que lhes são prestados.

É sempre delicada.

Suporta as consequências de seus atos.

Diz sempre a verdade sem restrição.

Esforça-se para dar uma boa impressão.

Sabe controlar-se.

Respeita a autoridade e é obediente aos seus superiores.

Faz o que é direito sem precisar ser advertida ou vigiada.

Gasta suas horas de lazer utilmente.

Não é dependente dos outros.

Aprecia os bons esportes.

Aprecia a boa música, boa literatura, boa arte e boa poesia. (Sem autoria)

Resoluções para todo o cristão

Ser diligente em ouvir e tardio em falar.

Ser verdadeiro e fiel, mas nunca intrigante.

Ser honesto, mas não se gabar.

Tratar a todos bem, mas escolher os amigos.

Saber brincar, mas também estudar

Ser sempre pontual

Respeitar a velhice, pois um dia seremos velhos

Ser bondoso até com animais.

Repartir suas alegrias e sentir-se feliz com a alegria dos outros

Não ser desconfiado, mas sempre cauteloso.

Esforçar-se pelo progresso, mas não invejando o alheio.

Seguindo os amigos só quando estiverem no bom caminho. (O Crisol, 1955, n. 2, p. 4)

Nota-se o quanto o discurso religioso ainda se confunde com o discurso de civilidades: ser educada significa também ser uma boa cristã, nada incomum lembrando o caráter confessional da instituição. A idéia de buscar um bom caminho, de cultivar valores como honestidade, bondade, equilíbrio nas ações e escolhas, de valorizar o estudo e o trabalho, buscar agir corretamente definem o que o Colégio Americano entendia como relevante para ser uma boa aluna.

A autorregulação é evidente: "merece a confiança do professor sem que ele precise estar vigilante" e "faz o que é direito sem precisar ser advertida ou vigiada". (O Crisol, 1955, n. 2, p. 5). Autocontrole, obediência, respeito às normas estabelecidas, cortesia, gratidão, esforço próprio são tidos como atributos de uma boa aluna. Não obstante, chamam atenção as atitudes: "Não é dependente dos outros" e "Sabe a razão pela qual frequenta o colégio" (O Crisol, 1955, n. 2, p. 5). O colégio estaria com essa prescrição estimulando-as a exercerem uma espécie de autonomia? Em que sentido? E a segunda norma, a escola entende a importância das alunas terem consciência do por que vinham para o Americano, algumas buscavam uma profissão, outras um refinamento intelectual, cultural. Será que elas tinham clareza disso?

Segundo Cunha (2007), a aprendizagem da civilidade fazia parte dos propósitos da escolarização. A escola deveria civilizar, portanto, disciplinar, prescrever, orientar as 
alunas para incorporarem, por meio de um processo de autorregulação, padrões comportamentais legitimados pela sociedade vigente.

Cabe ainda destacar a seção Você sabe que... por apresentar orientações de comportamento a serem seguidas pelas leitoras. Atitudes e manifestações de simpatia, postura cordial, cumprimento de regras emolduravam a moça bem educada. Um bom exemplo é este:

\begin{abstract}
Você sabe que... "uma jovem deve evitar grandes demonstrações em matéria de cumprimentos. Estes devem ser discretos, embora expressivos, acompanhados de um leve sorriso. Não se admite um gesto seco e impessoal numa jovem pois é mais correto e apropriado mostrar sempre um ar de simpatia. (O Crisol, out., 1953, n. 3, p. 5)
\end{abstract}

Assim, o desejo era que esses preceitos de civilidade permitissem a circulação de regras que visassem à formação do bom caráter e à construção de boas maneiras no sentido de produzir uma internalização das condutas prescritas.

\title{
Alguns arremates
}

A análise dos exemplares do periódico estudantil $O$ Crisol constituiu-se em um dispositivo privilegiado por expressar uma imagem dessas moças, autoras e leitoras do periódico, estudantes do Colégio Americano.

Ao longo do estudo procurou-se historicizar essas documentos, ou seja, analisar seus suportes materiais e seu corpus textual com o objetivo de mapear algumas práticas de escrita de alunas que representam um repertório de vivências escolares. Foi preciso desenvolver uma sensibilidade para analisar esses jornais, para poder indagá-los e problematizá-los. A partir de uma classificação do acervo consultado, como uma espécie de inventário, selecionou-se aquilo que, de alguma forma, interpelava a subjetividade da pesquisadora.

Ao ler cada exemplar, a idéia foi buscar uma aproximação das práticas de escrita daquelas moças como uma tentativa de apreender, por esse conjunto de textos, indícios de saberes e práticas escolares que evidenciavam as identidades femininas vigentes naquele período histórico. Na condição de pesquisadora entendo que perceber tais questões é um desafio que instiga a refletir sobre as relações e os discursos que nos constituem como sujeitos e que são apresentados nos textos circulantes nos periódicos e, muitas vezes, nas entrelinhas.

O Crisol era o órgão oficial das alunas do Colégio Americano, uma escola que nos anos 1940 e 1950 já atravessava diferentes gerações, em um tempo que as mulheres brasileiras apenas começavam a se inserir nos espaços de escolarização. Em suas diferentes edições, o periódico publicizava a instituição, colocando-a em uma posição de vanguarda, com destaque ao pioneirismo por oportunizar o acesso à profissionalização.

O Crisol, produzido por alunas, ex-alunas e seus professores, tematiza um pouco do universo daquelas jovens, evidenciando o seu envolvimento com os assuntos da escola, suas aprendizagens, seus desejos futuros. Neste sentido, evoca sistematicamente a história da fundadora do Colégio Americano, Carmem Chacon, que faleceu quase tão jovem como as alunas do Colégio, tornando-se-se um ícone da instituição de ensino, um 
exemplo e modelo de conduta inspirado. A representação que se faz de Chacon no periódico mostra uma jovem que reunia características de liderança, profissionalização, bondade, abnegação e altruísmo. Talvez sua trajetória representasse o desejo da escola de que as alunas seguissem nas trilhas de sua fundadora.

De forma sutil, nas entrelinhas, esses escritos mostram desvios, pequenas transgressões do ethos feminino, ao anunciar mudanças na vida das mulheres daquele tempo. Ao encerrar este texto, destaco o lema de escola que recorrentemente aparece em diferentes edições d'O Crisol: fui educada saberei viver. A frase de alguma forma sintetiza o significado da escolarização e para algumas da profissionalização em uma época de mudanças no estatuto das mulheres, as quais se consolidariam alguns anos mais tarde na sociedade brasileira.

\section{Referências}

BASSANEZI, Carla. Mulheres dos anos dourados. In: DEL PRIORE, Mary. História das mulheres no Brasil. São Paulo: Contexto, 2004, p. 607-639.

BASTOS, Maria Helena Camara. Espelho de papel: a imprensa e a história da educação. In. ARAUJO, José Carlos Souza; GATTI Jr. Décio (orgs.). Novos temas em história da educação brasileira: instituições escolares e educação na imprensa. Campinas: Autores Associados, 2002, p.151-174.

BURKE, Peter. O que é história cultural. Rio de Janeiro: Zahar, 2008.

CAMPOS, Raquel Discini. Mulheres e crianças na imprensa paulista (1920-1940). São Paulo: Unesp, 2009.

CUNHA, Maria Teresa Santos. No tom e no tema: escritas ordinárias na perspectiva da cultura escolar (segunda metade do século 20). In: Bencostta, Marcus Levy. Culturas escolares, saberes e práticas educativas. São Paulo: Cortez, 2007, p. 79-99.

FRAGO, Antonio Viñao. Por uma historia da cultura escrita: observações e reflexões. Cadernos de Projeto Museológico. Santarém: Escola Superior de Educação de Santarém, v. 1, n. 77, 2001.

GALVÃO, Ana Maria de Oliveira; LOPES, Elaine Marta Teixeira. Território plural: a pesquisa em história da educação. São Paulo: Ática, 2010.

GONÇALVES, Andrea Lisly. História e gênero. Belo Horizonte: Autêntica, 2006.

GOMEZ, Antonio Castillo. Historia de la cultura escrita: ideas para el debate. Revista Brasileira de História da Educação. Campinas: Autores Associados, 2003, v. 3, n. 1, p. 93124.

LE GOFF, Jacques. História e memória. Campinas: Unicamp, 1996.

LOURO, Guacira Lopes. Mulheres na sala de aula. In: DEL PRIORE, Mary. História das Mulheres no Brasil. São Paulo: Contexto, 2004, p. 443-481.

LUCA, Tania Regina de. História dos, nos e por meio dos periódicos. In. PINSKY, Carla Bassanezi (org.). Fontes históricas. São Paulo: Contexto, 2010, p. 111-153.

FISCHER, Beatriz Daudt. A professora primária nos impressos pedagógicos. In. STEPHANOU, Maria e BASTOS, Maria Helena Camara (orgs.). Histórias e memórias da educação no Brasil, v. 3. Petrópolis: Vozes, 2004, p. 324-335.

FONSECA, Thais Nivia de Lima e. História da educação e história cultural. In: VEIGA, 
Cynthia Greive; FONSECA, Thais Nivia de Lima e (orgs.). História e historiografia da educação no Brasil. Belo Horizonte, 2008, p. 49-75.

MACHADO, Juremir. Vozes da legalidade: política e imaginário na era do rádio. Porto Alegre: Sulina, 2011.

MESQUIDA, Peri. Hegemonia norte-americana e educação protestante no Brasil: um estudo de caso. Juiz de Fora: UFJF; São Bernardo do Campo: Editeo, 1994.

NÓVOA, Antonio. História da educação. Lisboa: Universidade de Lisboa, 1994. 286f. Tese (livre docência). Faculdade de Psicologia e Ciências da Educação, Universidade de Lisboa.

RANCIÉRE, Jacques. Sobre a história das mulheres no século 19. In: DUBY, George e PERROT, Michelle. As mulheres e a história. Lisboa: Rolo \& Filhos Artes Gráficas, 1995, p. 45-55.

DÓRIS BITTENCOURT ALMEIDA é doutora em Educação e professora adjunta de História da Educação na Faculdade de Educação da Universidade Federal do Rio Grande do Sul.

Endereço: Rua Lopo Gonçalves, 218/601 - 90050-350 - Porto Alegre - RS - Brasil.

E-mail: almeida.doris@gmail.com.

Recebido em 13 de julho de 2012.

Aceito em 7 de março de 2013. 